Check for updates

Cite this: RSC Adv., 2017, 7, 51910

Received 27th July 2017

Accepted 17th October 2017

DOI: $10.1039 / c 7 r a 08286 j$

rsc.li/rsc-advances

\section{Toxicity analysis of poly(sodium-4- styrenesulfonate) coated graphene on HMEC-1 cells under dynamic conditions mimicking blood flow'}

\author{
You-Long Chen, ${ }^{a}$ Ju-Yun Chiang, ${ }^{a}$ Hung-Tao Chou, ${ }^{a}$ Chien-Yu Fu, \\ Ying-Chieh Chen, (D) *a Chi-Young Lee, ${ }^{a}$ Nyan-Hwa Tai (D) *a and Hwan-You Chang*b
}

Graphene has been proven to have great potential in medical applications. The goal of this study is to evaluate the toxicity of graphene on human microvascular endothelial cells (HMEC-1) under flowing conditions mimicking blood circulation. Graphene was prepared by the electrochemical exfoliation method and conjugated with poly(sodium-4-styrenesulfonate) (PSS) to improve its hydrophilicity and dispersion behavior. Under static cell growth conditions, $80 \mathrm{mg} \mathrm{ml}^{-1}$ of graphene reduced cell viability to $60 \%$ of the control. Graphene was observed to aggregate on the cell surface by interacting with filopodia. In contrast, graphene applied to cells under flowing conditions showed no significant negative influence on the cells regardless of graphene concentration, incubation time, and the exerted shear force. Graphene also showed lower toxicity towards cells in a flowing culture than multi-walled carbon nanotubes (MWCNTs) and carbon black. Together, these results suggest that the prolonged interaction of graphene with the cell surface is critical in causing cell damage. The lower circulatory toxicity of graphene compared to MWCNTs and carbon black also suggests that graphene is more suitable for use in drug delivery systems.

\section{Introduction}

Nanotechnology is a rapidly developing research field that provides new opportunities, which are likely to revolutionize the future of medicine. The application of nanomaterials in biomedicine is particularly exciting due to their ability to pass through biological barriers, making them attractive substances for use in potential treatments. Taking cancer treatment as an example, nanomaterials may be developed into platforms to assist in the processes of diagnosis, surgery, radiation therapy, and chemotherapy. ${ }^{\mathbf{1}}$

Graphene is an atomic layer of carbons that are arranged in a hexagonal structure ${ }^{2}$ and has drawn considerable attention for its potential applications in biomedicine. Graphene has a high specific surface area, extraordinary thermal conductivity, high electron mobility, strong mechanical strength, ${ }^{3-6}$ and can be modified with various functional groups (epoxide, hydroxyl, and carboxyl groups) on its large planar surface area for the efficient

${ }^{a}$ Department of Materials Science and Engineering, National Tsing Hua University, Hsin-chu, Taiwan, 30013. E-mail: nhtai@mx.nthu.edu.tw; yisschen@mx.nthu.edu. tw; Tel: +88635715131 ext. $72763 ;+88635742568$

${ }^{b}$ Department of Medical Science, National Tsing Hua University, Hsin-chu, Taiwan, 30013. E-mail: hychang@mx.nthu.edu.tw; Tel: +886 35742910

$\dagger$ Electronic supplementary information (ESI) available. See DOI: 10.1039/c7ra08286j loading of drug molecules via $\pi-\pi$ stacking. Moreover, it has been demonstrated that graphene of a controllable size that possesses excellent photothermal/photodynamic properties could cross the cell membrane through active transport in different cell types, making graphene an ideal carrier for drug targeting, ${ }^{7-11}$ medical imaging, ${ }^{7,11,12}$ photothermal therapy, ${ }^{11,13-15}$ and accelerating stem cell differentiation. ${ }^{16}$

Prior to its use in clinical applications, it is necessary to determine whether graphene causes cytotoxicity. Some articles have been published showing the cytotoxicity of graphene in vitro ${ }^{17-21}$ and in vivo. ${ }^{22,23,28}$ These findings demonstrated the existence of dose- and size-dependent cytotoxicity both in vitro and in vivo; however, some researchers do not agree with these findings. The controversial issue of cytotoxicity and biocompatibility must be resolved in order to apply this nanomaterial in clinical applications.

Unfortunately, the in vitro models for assessing the cytotoxicity of graphene, such as cultured monolayer cells, may not correlate well with the complex and dynamic nature of the in vivo environment. Recent advances in microfluidic systems, which may provide an environment mimicking that in vivo, can facilitate more accurate drug testing ${ }^{\mathbf{2 4 , 2 5}}$ and thus can be used to further understand graphene cytotoxicity. The goal of this study is to investigate how graphene interacts with endothelial cells in circulation. It is believed that more relevant information 
concerning the behavior of graphene in the human body could be obtained by using a microfluidic chip to grow cells under conditions mimicking blood flow.

\section{Experimental}

\subsection{PSS-graphene preparation and characterization}

The electrochemical exfoliation method was used to produce PSS-graphene. First, polystyrene sulfonate (PSS) was dispersed in water by sonication for $30 \mathrm{~min}$ and used as an electrolyte in the following electrochemical exfoliation processes. Two graphite rods were used as electrodes in a vertical orientation and were separated by $5 \mathrm{~cm}$ in a $0.001 \mathrm{M}$ PSS solution. A direct current voltage of $5 \mathrm{~V}$ was used during the electrolysis process and carbon flakes gradually exfoliated from the anode, resulting in a suspension containing PSS-graphene after $6 \mathrm{~h}$ of sonication. Subsequently, the uniform suspension was vacuum filtered through both a $1 \mu \mathrm{m}$ and a $220 \mathrm{~nm}$ porous membrane to remove residual PSS and to obtain filtrate PSS-graphene with expected sizes.

To prepare PSS-f-MWCNTs and PSS-f-carbon black, both MWCNTs and carbon black were adopted as starting materials and were functionalized before conjugating PSS. MWCNTs with a weight of $0.2 \mathrm{~g}$ were added to a $100 \mathrm{ml}$ mixture of sulfuric acid and nitric acid ( $3: 1$ by volume) and subjected to stirring in a water bath at $80^{\circ} \mathrm{C}$ for $4 \mathrm{~h}$. Subsequently, the f-MWCNTs were washed to neutrality using deionized water and sonicated with PSS solution to ensure that f-MWCTs were successfully conjugated to PSS (PSS-f-MWCNTs or PSS-MWCNT). Finally, centrifugation was used to remove the excess PSS. The aforementioned process was also applied to prepared PSS-fcarbon black (PSS-carbon black).

To characterize the micromorphology after functionalization of PSS, a field emission scanning electron microscope (FE-SEM; JEOL JSM-6500F) and an atomic force microscope (AFM; Veeco Nanoscope 3100) were used. Raman spectroscopy (Jobin Yvon LabRam HR-800/632.8 nm He-Ne laser) was used to analyze the quality of the material, and Fourier transform infrared (FTIR) spectroscopy (Perkin-Elmer Spectrum RX) was used to examine the presence of functional groups on the graphene surface. The lateral sizes and dispersion behavior of the PSS-graphene were analyzed using the Zeta-sizer (Malvern) equipped with a dynamic light scattering system.

\subsection{Microfluidic chip fabrication}

The channel in the microfluidic chip was $1 \mathrm{~mm}$ long, $200 \mu \mathrm{m}$ wide, and $500 \mu \mathrm{m}$ high. The microfluidic chip was fabricated with poly(dimethylsiloxane) (PDMS; Sylgard 184, Dow Corning) and bonded to a glass slide. The PDMS base was mixed with a curing agent in a $10: 1$ ratio, casted on a self-designed mold, degassed in a vacuum, and cured at $80^{\circ} \mathrm{C}$ for $2 \mathrm{~h}$. The glass slide was washed using acetone, alcohol, and double distilled water. The PDMS layer was permanently bonded onto a glass slide using oxygen plasma treatment at $70 \mathrm{~W}$ for $10 \mathrm{~s}$. The chip was then heated to $150{ }^{\circ} \mathrm{C}$ for $20 \mathrm{~min}$ to enhance the bonding between PDMS and the glass slide. For the following cell culture experiments, the microfluidic chip was sterilized by rinsing sequentially with $75 \%$ and $95 \%$ ethanol and placed under UV light for $3 \mathrm{~h}$ to ensure sterility.

\subsection{Cell culture}

The human microvascular endothelial cell line (HMEC-1) bought from ATCC were maintained at $37{ }^{\circ} \mathrm{C}\left(5 \% \mathrm{CO}_{2}, 95 \%\right.$ air) in a 1:1 mixture of Dulbecco's modified Eagle's minimal essential medium (DMEM) and MCDB 131 (Gibco) and supplemented with $10 \%$ fetal bovine serum, $1 \%$ penicillin and streptomycin, $1 \% \mathrm{~L}$-glutamine, $1 \mu \mathrm{g} \mathrm{ml} \mathrm{m}^{-1}$ hydrocortisone, and $10 \mathrm{ng} \mathrm{ml}^{-1}$ epidermal growth factor.

For the cytotoxicity test, the channel of the microfluidic chip was coated with fibronectin (Invitrogen) $\left(100 \mu \mathrm{g} \mathrm{m}{ }^{-1}\right)$ at $37^{\circ} \mathrm{C}$ for $1 \mathrm{~h}$ to enhance cell attachment. The HMEC-1 cells were trypsinized from the culture dish, adjusted to a density of $2 \times$ $10^{6}$ cells per $\mathrm{ml}$, then injected into the channels and incubated for $2 \mathrm{~h}$ to obtain attachment. Cells not adhered to the substrate were washed away with fresh medium, and cells in the channel were fed every $12 \mathrm{~h}$ until starting the experiment.

\subsection{Static cytotoxicity test}

Approximately 15000 HMEC-1 cells were plated on each T96 flask and treated separately with different concentrations of PSS-graphene for $4 \mathrm{~h}$ prior to being analyzed for their viability by the MTS assay. The morphology of the cells treated with PSSgraphene was examined using FE-SEM and laser scanning confocal microscopy. The treated cells were washed with PBS, immersed in Karnovsky's fixative and 1\% osmium tetroxide for fixation, and then dehydrated sequentially with gradually increasing concentrations of ethanol $(20,40,50,70,90$, and $100 \%$ ). Finally, the cells were transferred to a critical point dryer and coated with Pt before observation.

This study utilized scanning laser confocal microscopy to investigate PSS-graphene, PSS-MWCNT and PSS-carbon black uptake by the cells. First, PSS-graphene, PSS-MWCNT or PSScarbon black were conjugated with Dylight 488 NHS ester (Thermo Scientific) according to the manufacturer's manual, dispersed in the culture medium, and incubated with HMEC-1 cells for $2 \mathrm{~h}$. The stability of PSS-graphene-Dylight 488 is maintained for at least 2 days in the culture (Fig. S1†). After fixation, the specimens were stained with DAPI for $10 \mathrm{~min}$, mounted on glass slides, and then examined using a laser scanning confocal microscope.

\subsection{Toxicity of graphene to cells cultured under dynamic flow conditions in the microfluidic channel}

Different concentrations of PSS-graphene, PSS-f-MWCNTs, and PSS-f-carbon black were injected into the microfluidic channels at flow rates controlled by a syringe pump. The shear stress applied to the cells was calculated by eqn (1).

$$
\tau=\frac{6 \eta Q}{w h^{2}}
$$

where $\eta, Q, w$, and $h$ were dynamic viscosity of the medium (1 $\mathrm{cP})$, flow rate, channel width, and channel height, respectively. ${ }^{26}$ 
A Live/Dead Cell Viability Assay kit (Thermal-Fisher Scientific) was used to evaluate the viability of HMEC-1 cells inside the microfluidic channel after completing the experiments.

\subsection{Statistical analysis}

All experiments were repeated twice with at least four replicates in each repetition. For comparative studies, student's $t$-test was used for statistical analysis. Differences were considered statistically significant if $p<0.05$.

\section{Results and discussion}

\subsection{Characterization of PSS-graphene}

Poly(sodium-4-styrenesulfonate) (PSS) is a cation exchange polyelectrolyte commonly used to produce mechanically stable and reproducible coatings on various materials. When grafted on graphene, PSS not only prevents graphene flakes from restacking via van der Waals forces, but also dramatically improves the hydrophilicity. PSS is noncytotoxic and may be applied in drug delivery. ${ }^{27}$
The functional groups on the surface of graphene, determined by FTIR spectrometry, are shown in Fig. 1a. PSS-graphene has broadened peaks at 1653, 1114, 1053, and $684 \mathrm{~cm}^{-1}$, indicating the presence of $\mathrm{S}=\mathrm{O}, \mathrm{C}-\mathrm{S}, \mathrm{S}-\mathrm{OH}$, and aromatic rings, respectively. These peaks were also found in PSS, indicating the successful grafting of PSS anions to the exfoliated graphite surface during the electrochemical exfoliation process. The peak at $1697 \mathrm{~cm}^{-1}$ shown for PSS-graphene is attributed to $\mathrm{C}=$ $\mathrm{O}$, reflecting the oxidation reaction that occurred during the electrochemical exfoliation process.

For graphene with a few layers, the peak at $1320 \mathrm{~cm}^{-1}(\mathrm{D}-$ band) reflects the defects of the graphite material, and the peak at $1580 \mathrm{~cm}^{-1}$ (G-band) signifies the $\mathrm{sp}^{2}$ hybridization of graphitic carbon. The 2D-band at $2650-2670 \mathrm{~cm}^{-1}$ is attributed to two phonon double resonance modes. The relative intensity ratio of $2 \mathrm{D}$ - and G-bands $\left(I_{2 \mathrm{D}} / I_{\mathrm{G}}\right)$ is an index of the layer number of the synthesized graphene. The Raman spectrum of the PSSgraphene (Fig. 1b) clearly indicates that the D-band is higher than the G-band, showing that the structure of the PSS-graphene contains amorphous carbon and defects generated by the
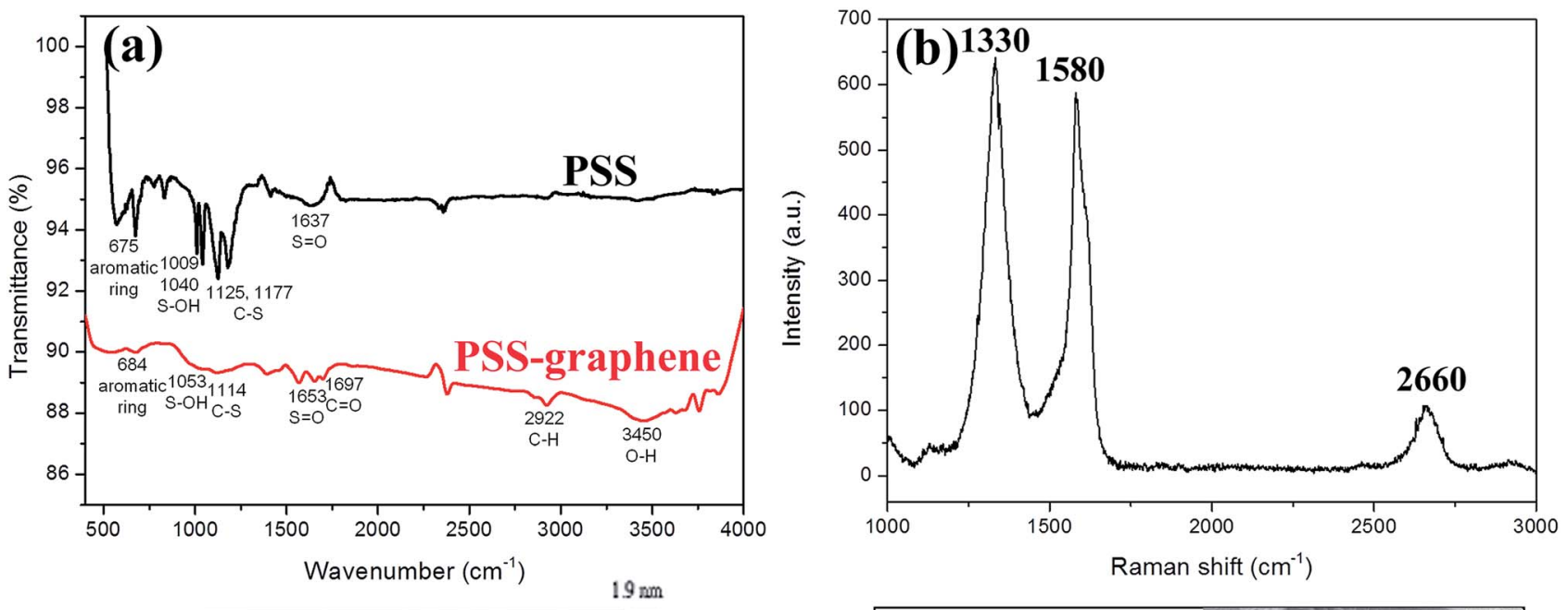

(c)
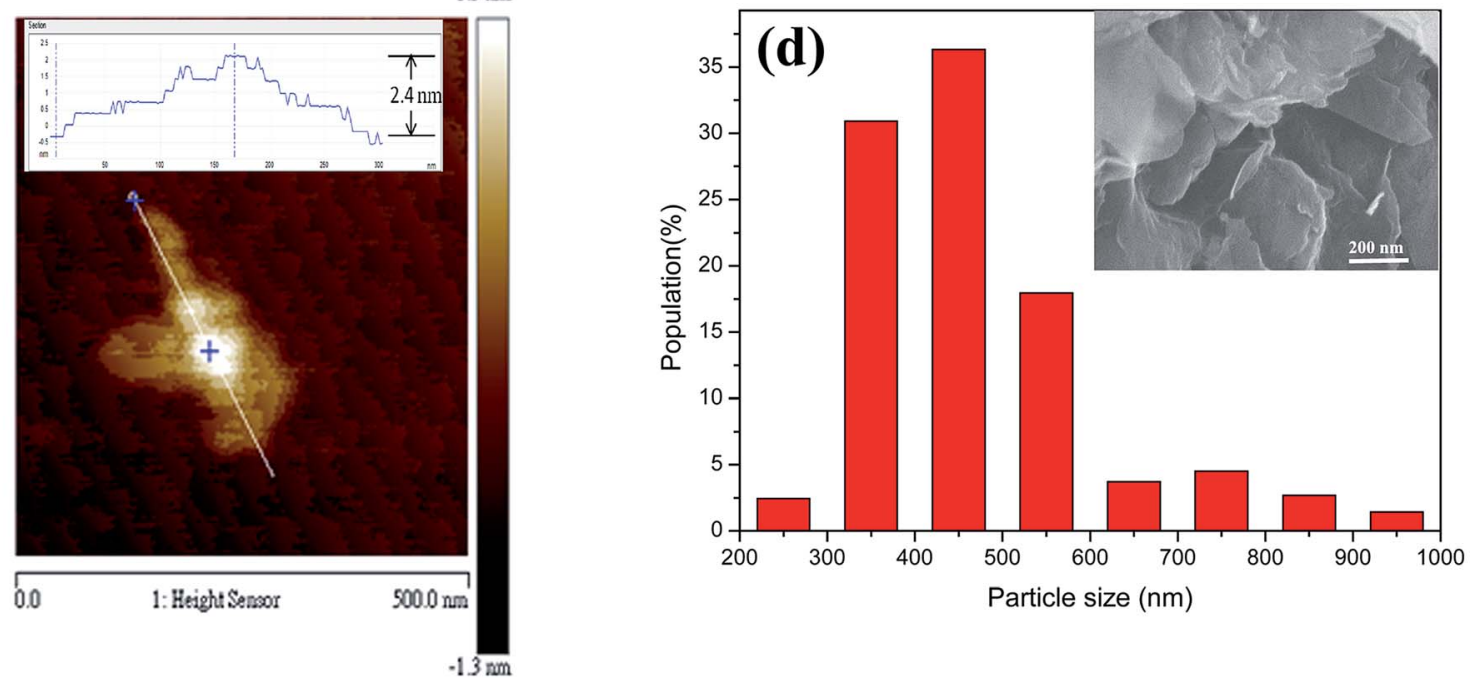

Fig. 1 Characterization of chemical and physical properties of PSS-graphene. (a) FTIR spectrum of PSS and PSS-graphene, (b) Raman spectrum of PSS-graphene, (c) AFM images of PSS-graphene (the inset picture shows the cross-sectional height profile of the PSS-graphene), and (d) lateral size distribution (bottom) and morphology (inset) of PSS-graphene. 


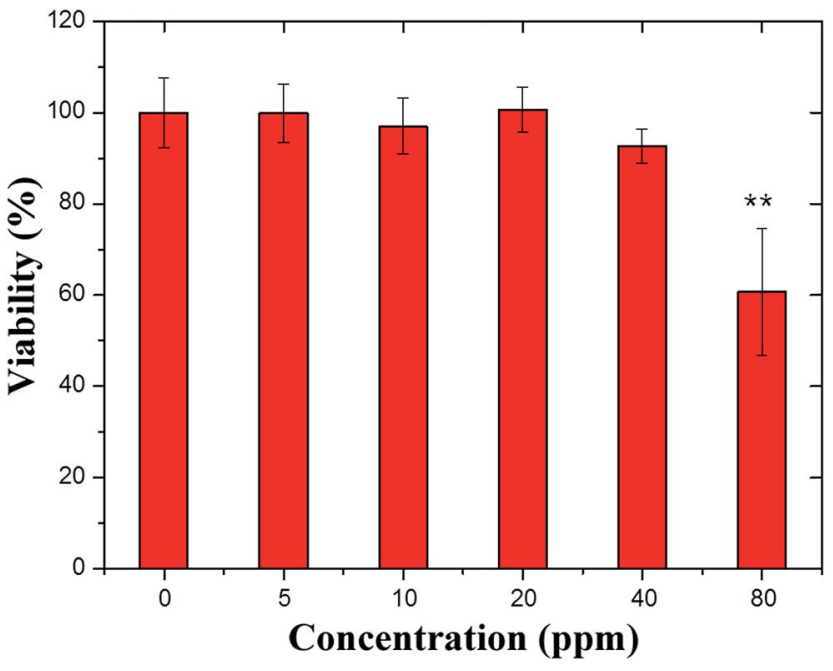

Fig. 2 Effects of different concentrations of PSS-graphene on HMEC1 viability under static conditions. The cell viability was determined by MTS assay. * indicates $p<0.05$.

electrochemical exfoliation process. Compared to the $I_{2 \mathrm{D}} / I_{\mathrm{G}}$ ratio of 1.5 to 2 reported for single-layer graphene, the $I_{2 \mathrm{D}} / I_{\mathrm{G}}$ ratio of PSS-graphene synthesized in this study was approximately 0.26. It was therefore estimated that the PSS-graphene fabricated through the electrochemical exfoliation processes is a multiple-layer graphene. This result is consistent with that obtained from AFM and SEM (Fig. 1c and inset of Fig. 1d), which is widely used for analyzing the thickness of graphene. The AFM result showed that the thickness of the PSS-graphene was approximately $2.4 \mathrm{~nm}$. The size distribution of the obtained PSS-graphene ranged from 200 to $600 \mathrm{~nm}$, as shown in Fig. 1d. The dispersion behavior in the DD water was obtained, and the zeta potential of dispersed PSS-graphene was $-30 \mathrm{mV}$; this suggests that the PSS-graphene is highly hydrophilic and could stably disperse in DD water.

\subsection{Cytotoxicity of HMEC-1 cells incubated with PSS- graphene under a static state}

Different concentrations of PSS-graphene were tested on HMEC-1 cells, and cell viability was measured by cell proliferation (MTS) assay (Promega) after 24 hours of static culture, as shown in Fig. 2. At concentrations of 5, 10, 20, and $40 \mathrm{mg} \mathrm{ml}^{-1}$, PSS-graphene did not result in detectable damage to the HMEC-1 cells. Conversely, HMEC-1 cells incubated with $80 \mathrm{mg}$ $\mathrm{ml}^{-1}$ of PSS-graphene showed a death rate of up to $40 \%$.

The gross cell morphology reflecting the general health status of the cells was also examined through optical microscopy. The images shown in Fig. 3 also indicate no obvious difference between normal and 5, 10, 20, and $40 \mathrm{mg} \mathrm{ml}^{-1}$ PSSgraphene-treated HMEC-1 cells, even when black agglomerates could be clearly observed on the cell surface. Consistent with
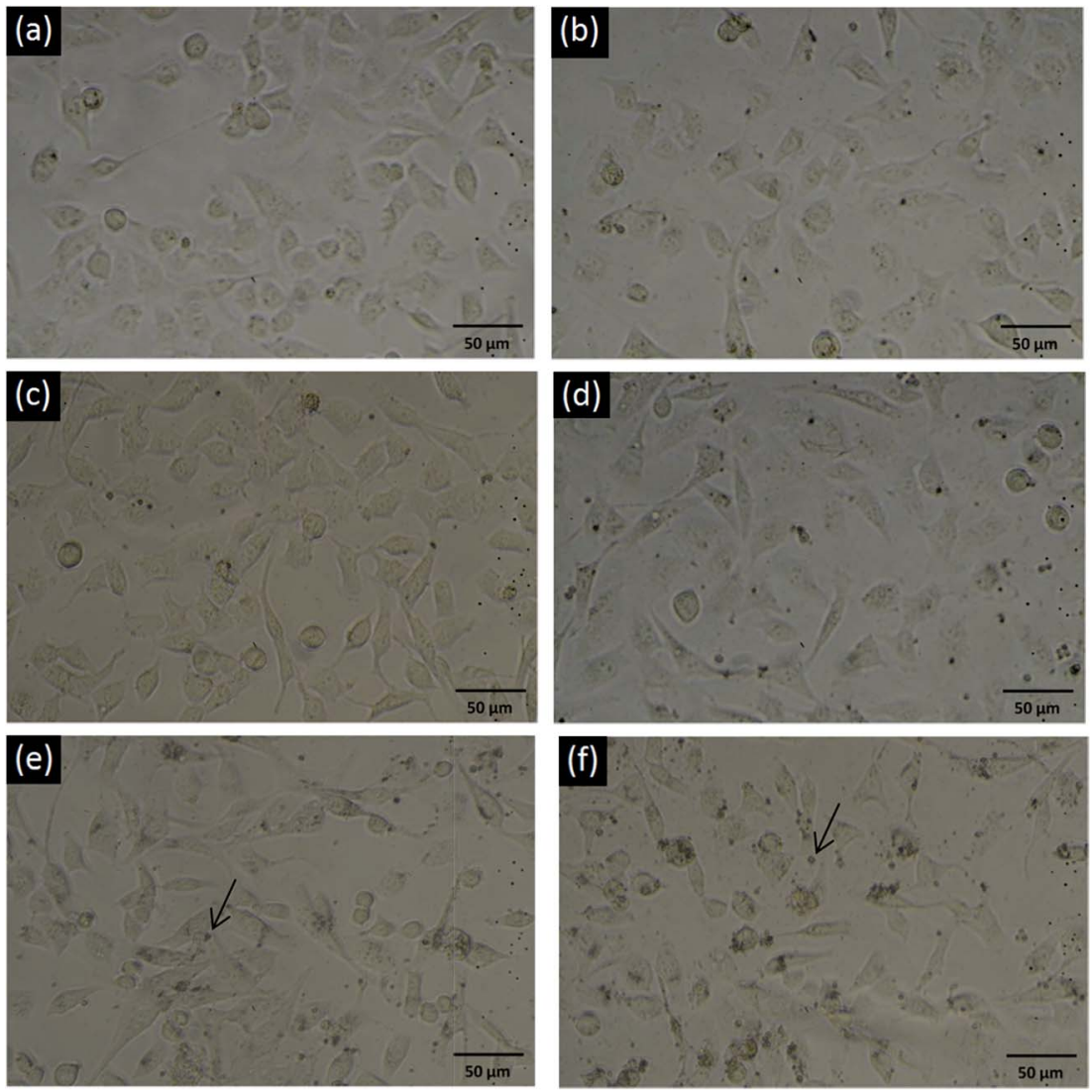

Fig. 3 Optical microscopy images of PSS-graphene-treated HMEC-1 cells under static conditions. (a) $0 \mathrm{mg} \mathrm{ml}^{-1}$; (b) $5 \mathrm{mg} \mathrm{ml}^{-1}$; (c) $10 \mathrm{mg} \mathrm{ml}^{-1}$; (d) $20 \mathrm{mg} \mathrm{ml}^{-1}$; (e) $40 \mathrm{mg} \mathrm{ml}^{-1}$; (f) $80 \mathrm{mg} \mathrm{ml}^{-1}$. The arrows indicate PSS-graphene. 


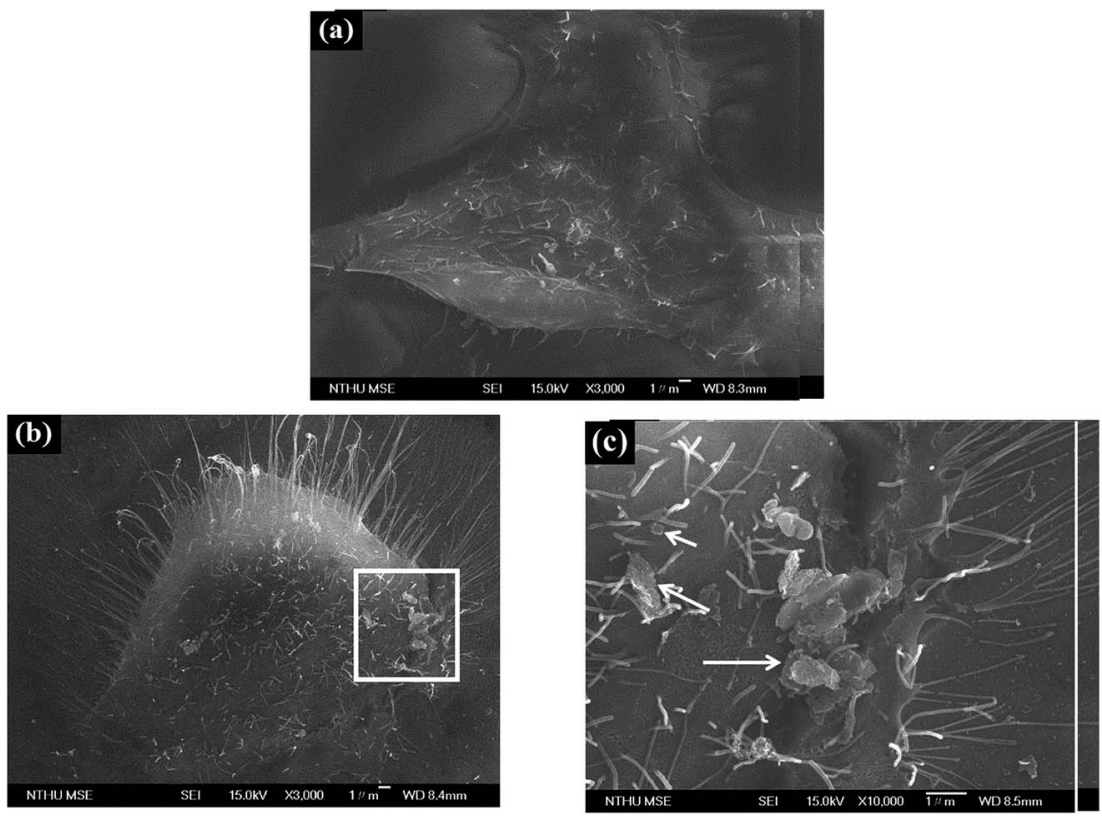

Fig. 4 Effects of PSS-graphene treatment on HMEC-1 cell morphology. SEM images of the cells (a) without and (b) with PSS-graphene for $4 \mathrm{~h}$. (c) Magnified image of the area boxed in (b). The arrows indicate PSS-graphene.
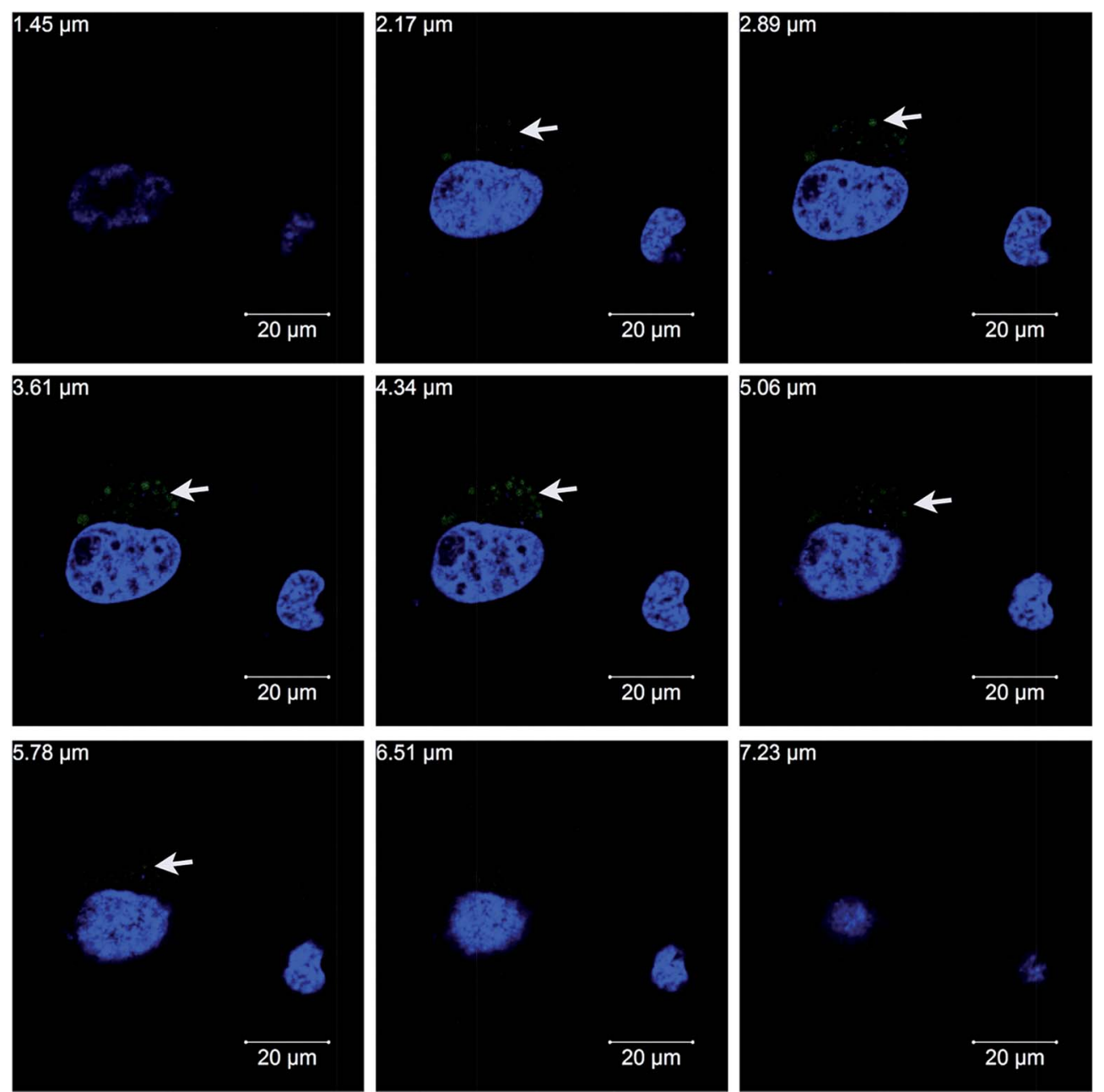

Fig. 5 Confocal microscopic images of the uptake of PSS-graphene into HMEC-1 cells with continuous longitudinal section planes ranging from 1.45-7.23 $\mu \mathrm{m}$. The nuclei were stained blue (DAPI) and PSS-graphene-Dylight 488 exhibits a green color. 
the finding of the MTS assay, cells treated with $80 \mathrm{mg} \mathrm{ml}^{-1}$ PSSgraphene exhibited a less rounded morphology, reflecting poor physiology of the cells.

Fig. 4 depicts the microstructure of HMEC-1 cells after incubating with graphene. The untreated HMEC-1 cells are shown in Fig. 4a. PSS-graphene accumulated by entangling with filopodia on the surface of the HMEC-1 cells after treatment with PSS-graphene for $4 \mathrm{~h}$ (Fig. 4b). According to previously published articles, nanomaterials with a lateral size of $350 \mathrm{~nm}$ could penetrate the cell membrane through phagocytosis with the assistance of filopodia. ${ }^{29}$ In this regard, we speculated that the PSS-graphene with a similar lateral size is very likely to be phagocytosed by HMEC- 1 cells after adhering to the cell surface. (a) PSS-graphene

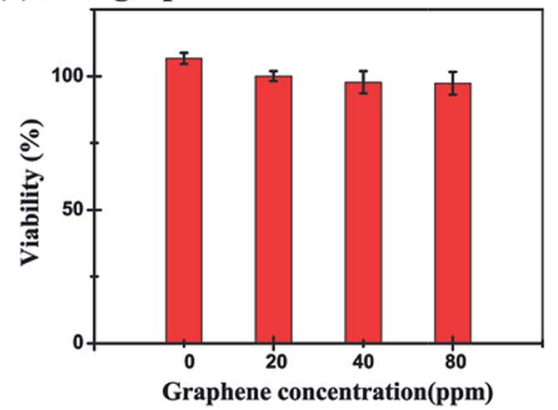

(b)10 dynes $/ \mathrm{cm}^{2}$

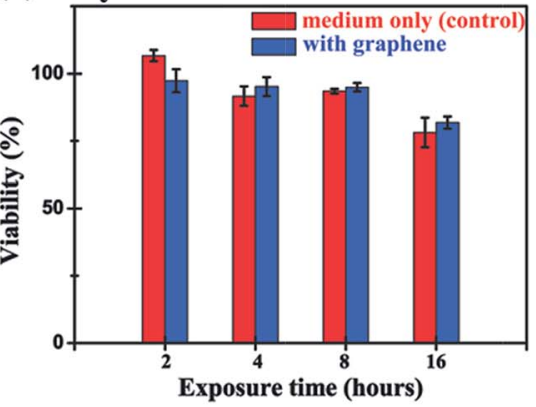

(c) 20 dynes $/ \mathrm{cm}^{2}$

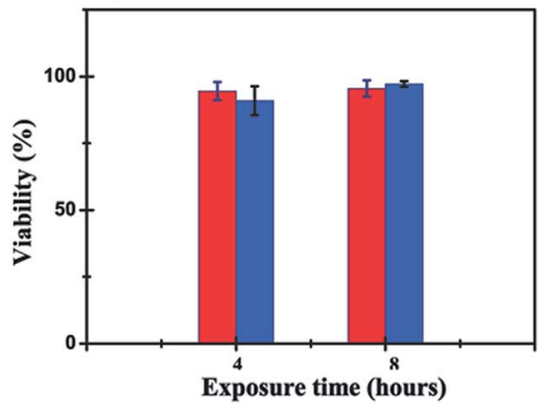

Fig. 6 Effects of different concentration of PSS-graphene, exposure time periods, and shear stress on HMEC-1 cell viability under dynamic conditions. (a) Exposure of the cells to different concentrations of PSS-graphene under 10 dynes per $\mathrm{cm}^{2}$ of shear stress for $2 \mathrm{~h}$. (b) The effect of treatment time on the viability of HMEC-1 cells in the presence of $80 \mathrm{mg} \mathrm{ml}^{-1}$ of PSS-graphene at a fixed 10 dynes per $\mathrm{cm}^{2}$ shear stress. (c) HMEC-1 cell viability grown under a shear stress of 20 dynes per $\mathrm{cm}^{2}$ and exposure times of $4 \mathrm{~h}$ and $8 \mathrm{~h}$ in the presence of $80 \mathrm{mg} \mathrm{ml}^{-1}$ PSSgraphene. $(*, p<0.05 ; * *, p<0.005 ; * * *, p<0.001)$.
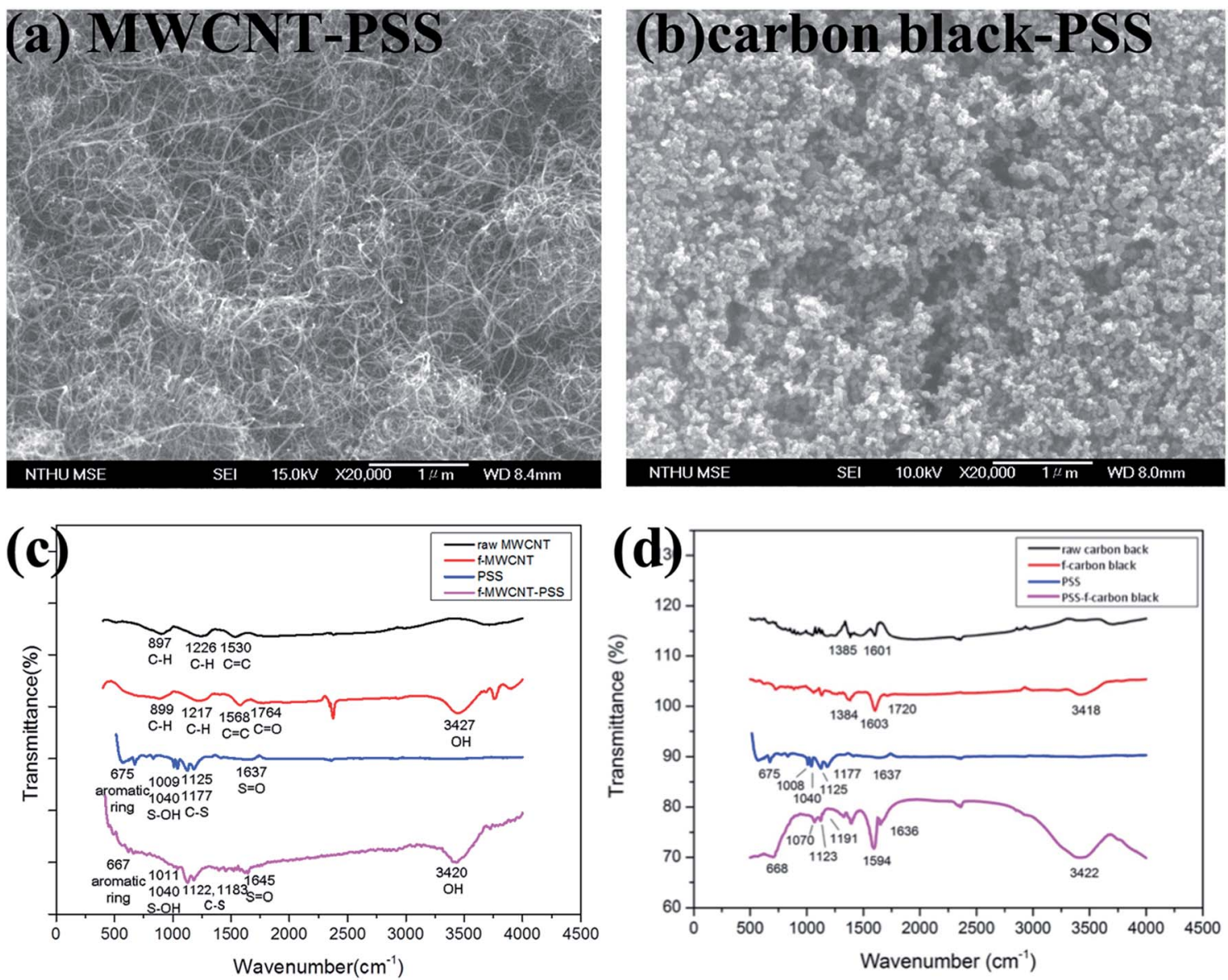

Fig. 7 (a) Surface morphology and (c-d) FTIR spectrum of MWCNT-PSS (a and c) and carbon black-PSS (b and d). 
To investigate whether PSS-graphene can penetrate into cells, PSS-graphene was first conjugated with Dylight 488 and confocal microscopy was then utilized to verify the subcellular location of the materials. Results shown in Fig. 5 demonstrated that PSS-graphene-Dylight 488 (green, marked with arrows) could be detected in the same longitudinal section plane as the nucleus (blue), suggesting that HMEC-1 cells phagocytosed PSS-graphene.
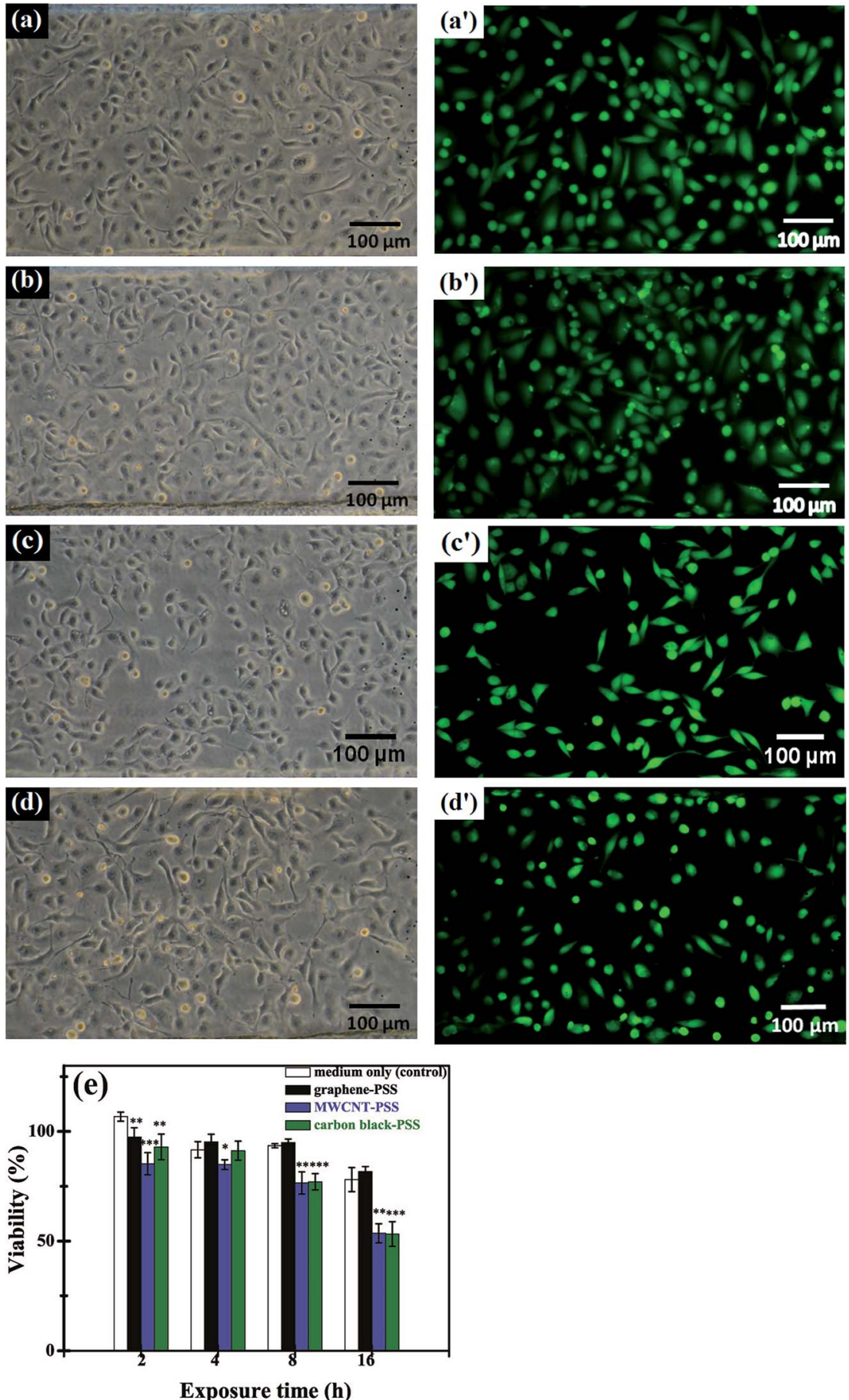

Fig. 8 Effect of carbon nanomaterials on HMEC-1 cells grown under flowing dynamic conditions. The HMEC-1 cells were exposed to 10 dynes per $\mathrm{cm}^{2}$ of shear stress for $16 \mathrm{~h}$ in: (a) a regular culture medium without any treatment (control) and with (b) $80 \mathrm{mg} \mathrm{ml}^{-1}$ PSS-graphene, (c) $80 \mathrm{mg}$ $\mathrm{ml}^{-1}$ PSS-f-MWCNTs, and (d) $80 \mathrm{mg} \mathrm{m}^{-1}$ PSS-f-carbon black. The photos shown in (a), (b), (c), and (d) were pictured using bright field microscopy before the experiment and $\left(a^{\prime}\right),\left(b^{\prime}\right),\left(c^{\prime}\right)$, and $\left(d^{\prime}\right)$ were pictured under a fluorescence microscope after staining the cells. (e) Comparison of the viability of HMEC-1 cells after treatment with $80 \mathrm{mg} \mathrm{ml}^{-1}$ PSS-graphene, PSS-f-MWCNTs, and PSS-f-carbon black at 10 dynes per $\mathrm{cm}^{2}$ of shear stress for different periods of time. Data showing significant differences from that of the controls are marked with asterisks (*,p<0.05; **, $p<0.005 ; * * *, p<0.001)$. 


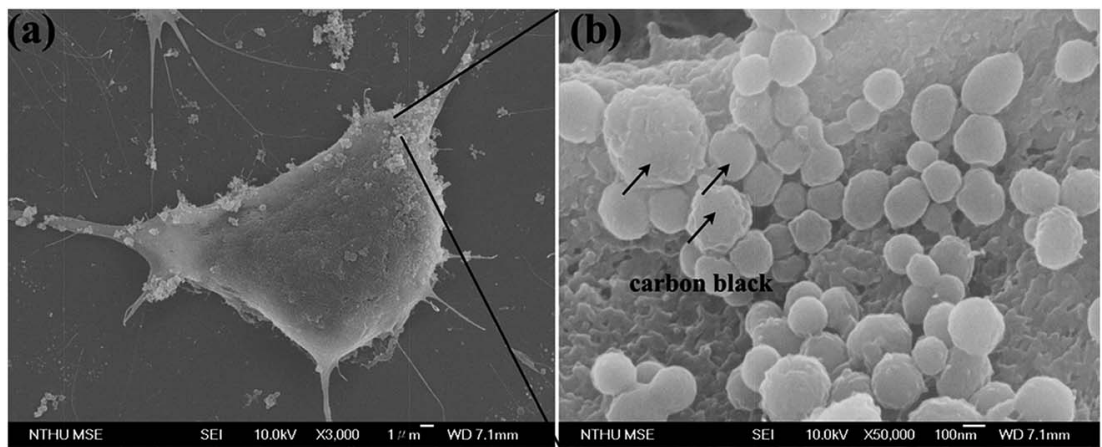

Fig. 9 Effects of PSS carbon black treatment on HMEC-1 cell morphology under dynamic condition. (a) Low and (b) enlarged magnification SEM image of the cells treated with PSS-carbon black.

\subsection{Cytotoxicity of HMEC-1 cells incubated with PSS- graphene under dynamic conditions}

A microfluidic chip equipped with a microchannel was used to evaluate the cytotoxicity of PSS-graphene to HMEC-1 cells under flowing conditions to simulate blood flow and the shear stress exerted on the vessel walls. Fig. $6 a$ and $7 a$ show the morphology of normal HMEC-1 cells grown in the microchannel under a shear stress of 10 dynes per $\mathrm{cm}^{2}$. Interestingly, HMEC-1 cells grown under the same flow rates in the medium containing $80 \mathrm{mg} \mathrm{ml}^{-1}$ PSS-graphene did not display obvious differences in cell number (Fig. 6a and b) or morphology (Fig. 7b) compared to those grown in the absence of a PSSgraphene control. Treatment of the cells for longer periods gradually decreased cell viability; however, little difference was observed between the results of the control and the PSS-graphene treated sets (Fig. 6b). Increasing the shear force to 20 dynes per $\mathrm{cm}^{2}$ did not yield significant differences in cell viability between the control and PSS-graphene treated sets (Fig. 6c) after either $4 \mathrm{~h}$ or $8 \mathrm{~h}$ of incubation. This finding is in contrast to what was observed for cells grown under static culture conditions, where only $60 \%$ of the HMEC- 1 cells remained alive after incubation with $80 \mathrm{mg} \mathrm{ml}^{-1}$ of PSS-graphene (Fig. 2). This result strongly suggests that under static conditions, PSS-graphene will likely cause cell damage. It is likely that PSS-graphene with smaller lateral sizes will be phagocytosed via filopodia, and therefore contribute a negative influence on the HMEC-1 cells. The cytotoxicity of cells grown in a flowing culture with PSS-graphene mimicking blood circulation with a shear stress of $10-20$ dynes per $\mathrm{cm}^{2}$ decreased. These results imply that the longer time period PSS-graphene accumulated and adhered on the cell membranes, the higher cell cytotoxicity PSS-graphene caused.

\subsection{Cytotoxicity of HMEC-1 cells incubated with various PSS- carbon nanomaterials under dynamic conditions}

It has been previously demonstrated that both the shape and extent of the agglomeration of carbon nanomaterials are critical conditions influencing cell damage under static condition. To investigate the geometry effect of carbon nanomaterials under dynamic conditions on the HMEC-1 cells, PSS-functionalized graphene, PSS-functionalized MWCNT (MWCNT-PSS, Fig. 7a and c) and PSS-functionalized carbon black (carbon black-PSS, Fig. $7 \mathrm{~b}$ and d) were synthesized and characterized by SEM and FITR. Fig. 7c showed the FTIR spectra of the raw MWCNTs, fMWCNTs, and PSS-f-MWCNT. The peaks at $3427 \mathrm{~cm}^{-1}(\mathrm{O}-\mathrm{H}$ group) and $1764 \mathrm{~cm}^{-1}(\mathrm{C}=\mathrm{O}$ bond) resulting from functionalization were observed, and the peaks at $1645 \mathrm{~cm}^{-1}(\mathrm{~S}=\mathrm{O})$, $1183 \mathrm{~cm}^{-1}$ (C-S), $1122 \mathrm{~cm}^{-1}$ (C-S), $1011 \mathrm{~cm}^{-1}$ (S-OH) and $667 \mathrm{~cm}^{-1}$ (aromatic ring) ensured that the $\mathrm{f}$-MWCNTs were conjugated to PSS. Fig. 7d shows the FTIR spectra of the raw carbon black, f-carbon black and PSS-f-carbon black. The spectrum of f-carbon black has a broad band at $3418 \mathrm{~cm}^{-1}$ for the $\mathrm{O}-\mathrm{H}$ stretching vibration and a small band at $1720 \mathrm{~cm}^{-1}$ for carbonyl $\mathrm{C}=\mathrm{O}$ stretching vibration, indicating that raw carbon black were successfully functionalized. Besides, in the spectrum of PSS-f-carbon black, the characteristic bands at 1636, 1191, 1123 and $1070 \mathrm{~cm}^{-1}$ are related to the $\mathrm{S}=\mathrm{O}, \mathrm{C}-\mathrm{S}, \mathrm{C}-\mathrm{S}, \mathrm{S}-\mathrm{OH}$ stretching modes, respectively, and $668 \mathrm{~cm}^{-1}$ can be attributed to aromatic ring in PSS.

Cells treated with different carbon nanomaterials, including PSS-graphene (Fig. 8b), PSS-f-MWCNT (Fig. 8c), and PSS-fcarbon black (Fig. 8d), were tested under dynamic flowing conditions at a concentration of $80 \mathrm{mg} \mathrm{ml}^{-1}$ and a shear stress of 10 dynes per $\mathrm{cm}^{2}$ to verify the impact of carbon nanomaterial shapes on cell viability under flowing conditions. Fig. 8e illustrates that in as short as a $2 \mathrm{~h}$ exposure time, the viability of both PSS-f-MWCNTs and PSS-f-carbon black treated cells was clearly lower than that of the control and the PSS-graphene treated cells. The negative effects caused by the PSS-f-MWCNTs and PSS-f-carbon black also became more dramatic with increasing incubation time (Fig. 8e). It has been previously proposed that the negative influence of MWCNTs on cultured cells in a flowing environment is due to its one-dimensional tubular structure that results in turbulent flow and an increased opportunity for its sharp ends to cause physical damage to the cells. It is less clear why PSS-f-carbon black also reduced HMEC-1 cell viability under such treatment conditions, although a large quantity of PSS-f-carbon black material was observed to have attached to the HMEC-1 cell surface in a dose-dependent manner, as depicted in the SEM images (Fig. 9). 


\section{Conclusions}

A comparative study on the toxicity of PSS-graphene to HMEC-1 cells under static and dynamic culture conditions was completed. Under static culture conditions, the functionalized graphene easily accumulated and aggregated on the cell membranes and then entered the cell plasma with assistance of filopodia through the process of phagocytosis, resulting in the death of the cells. The cytotoxicity of PSS coated graphene decreased if the cells were grown in a flowing culture mimicking blood circulation with a shear stress of 10-20 dynes per $\mathrm{cm}^{2}$. This study demonstrated that functionalized graphene shows lower toxicity towards cells cultured in a dynamic culture as compared with in a static culture. The cytotoxicity of functionalized graphene is also lower than that of other carbon nanomaterials, including MWCNTs and carbon black, in a dynamic flowing culture due to the lateral-size effect and dispersion behavior. More toxicological studies of this material at higher doses that make use of animal models are necessary before functionalized graphene-related materials can be tested clinically for drug delivery.

\section{Conflicts of interest}

There are no conflicts to declare.

\section{Acknowledgements}

This study was supported by the Ministry of Science and Technology (MOST), Taiwan under project number MOST 1052221-E-007-142 and MOST 106-2221-E-007-055, and by the National Tsing-Hua University under project no. 101N7049E1.

\section{References}

1 S. M. Moghimi, A. C. Hunter and J. C. Murray, FASEB J., 2005, 19, 311-330.

2 A. K. Geim and K. S. Novoselov, Nat. Mater., 2007, 6, 183-191. 3 C. Lee, X. D. Wei, J. W. Kysar and J. Hone, Science, 2008, 321, 385-388.

4 A. A. Balandin, S. Ghosh, W. Z. Bao, I. Calizo, D. Teweldebrhan, F. Miao and C. N. Lau, Nano Lett., 2008, 8, 902-907.

5 J. H. Chen, C. Jang, S. D. Xiao, M. Ishigami and M. S. Fuhrer, Nat. Nanotechnol., 2008, 3, 206-209.

6 Y. W. Zhu, S. Murali, W. W. Cai, X. S. Li, J. W. Suk, J. R. Potts and R. S. Ruoff, Adv. Mater., 2010, 22, 3906-3924.

7 X. M. Sun, Z. Liu, K. Welsher, J. T. Robinson, A. Goodwin, S. Zaric and H. J. Dai, Nano Res., 2008, 1, 203-212.

8 Z. Liu, J. T. Robinson, X. M. Sun and H. J. Dai, J. Am. Chem. Soc., 2008, 130, 10876-10877.

9 H. X. Wu, H. L. Shi, Y. P. Wang, X. Q. Jia, C. Z. Tang, J. M. Zhang and S. P. Yang, Carbon, 2014, 69, 379-389.
10 L. Y. Tian, X. B. Pei, Y. X. Zeng, R. He, Z. J. Li, J. Wang, Q. B. Wan and X. Y. Li, J. Nanopart. Res., 2014, 16, 14.

11 S. F. Mao, D. Gao, W. Liu, H. B. Wei and J. M. Lin, Lab Chip, 2012, 12, 219-226.

12 Y. Sheng, X. S. Tang, E. W. Peng and J. M. Xue, J. Mater. Chem. B, 2013, 1, 512-521.

13 Z. M. Markovic, L. M. Harhaji-Trajkovic, B. M. TodorovicMarkovic, D. P. Kepic, K. M. Arsikin, S. P. Jovanovic, A. C. Pantovic, M. D. Dramicanin and V. S. Trajkovic, Biomaterials, 2011, 32, 1121-1129.

14 K. Yang, S. A. Zhang, G. X. Zhang, X. M. Sun, S. T. Lee and Z. A. Liu, Nano Lett., 2010, 10, 3318-3323.

15 J. T. Robinson, S. M. Tabakman, Y. Y. Liang, H. L. Wang, H. S. Casalongue, D. Vinh and H. J. Dai, J. Am. Chem. Soc., 2011, 133, 6825-6831.

16 T. R. Nayak, H. Andersen, V. S. Makam, C. Khaw, S. Bae, X. F. Xu, P. L. R. Ee, J. H. Ahn, B. H. Hong, G. Pastorin and B. Ozyilmaz, ACS Nano, 2011, 5, 4670-4678.

17 Y. B. Zhang, S. F. Ali, E. Dervishi, Y. Xu, Z. R. Li, D. Casciano and A. S. Biris, ACS Nano, 2010, 4, 3181-3186.

18 A. Sasidharan, L. S. Panchakarla, A. R. Sadanandan, A. Ashokan, P. Chandran, C. M. Girish, D. Menon, S. V. Nair, C. N. R. Rao and M. Koyakutty, Small, 2012, 8, 1251-1263.

19 O. Akhavan, E. Ghaderi and A. Akhavan, Biomaterials, 2012, 33, 8017-8025.

20 Y. L. Chang, S. T. Yang, J. H. Liu, E. Dong, Y. W. Wang, A. N. Cao, Y. F. Liu and H. F. Wang, Toxicol. Lett., 2011, 200, 201-210.

21 M. Wojtoniszak, X. C. Chen, R. J. Kalenczuk, A. Wajda, J. Lapczuk, M. Kurzewski, M. Drozdzik, P. K. Chu and E. Borowiak-Palen, Colloids Surf., B, 2012, 89, 79-85.

22 K. Yang, H. Gong, X. Z. Shi, J. M. Wan, Y. J. Zhang and Z. Liu, Biomaterials, 2013, 34, 2787-2795.

23 K. Wang, J. Ruan, H. Song, J. L. Zhang, Y. Wo, S. W. Guo and D. X. Cui, Nanoscale Res. Lett., 2011, 6, 8.

24 D. Kim, Y. S. Lin and C. L. Haynes, Anal. Chem., 2011, 83, 8377-8382.

25 N. J. Kent, L. Basabe-Desmonts, G. Meade, B. D. MacCraith, B. G. Corcoran, D. Kenny and A. J. Ricco, Biomed. Microdevices, 2010, 12, 987-1000.

26 J. A. Simoes, D. M. Citron, A. Aroutcheva, R. A. Anderson, C. J. Chany, D. P. Waller, S. Faro and L. J. D. Zaneveld, Antimicrob. Agents Chemother., 2002, 46, 2692-2695.

27 A. H. Cory, T. C. Owen, J. A. Barltrop and J. G. Cory, Cancer Commun., 1991, 3, 207-212.

28 C. Bussy, H. Ali-Boucetta and K. Kostarelos, Acc. Chem. Res., 2013, 46, 692-701.

29 H. Yue, W. Wei, Z. G. Yue, B. Wang, N. N. Luo, Y. J. Gao, D. Ma, G. H. Ma and Z. G. Su, Biomaterials, 2012, 33, 40134021. 